\title{
DİVAN ŞAİRİ VARSAĞIYI FARKLI ANLARSA
}

\author{
Doç. Dr. İsrafil BABACAN \\ Yıldırım Beyazıt Üniversitesi, İnsan ve Toplum Bilimleri Fakültesi, \\ Türk Dili ve Edebiyatı Bölümü
}

\begin{abstract}
ÖZ
Çalışmamızda, XVII. asırda yaşamış Nurî mahlaslı İbrahîm Ziyâeddîn'in varsă̆ başlı̆̆ını taşıyan şiiri ele alınmıştır. Illk olarak halk şiiri geleneği içinde varsağının edebî bir terim olarak nasıl algılandı̆̆ı çeşitli kaynakların bakış açısıyla değerlendirilmiştir. Bu değerlendirme yapılırken varsağının bilinen tanım ve niteliklerinin aktarımından kaçınılmış, edebî bir terim olarak ön plana çıkan yönleri vurgulanmıştır. Daha sonra divan şairlerinin halk şiiri niteliklerine ve varsağıya yaklaşımı ele alınmıştır. Söz konusu yaklaşımın Azerbaycan coğrafyasında oluşan klasik şiir içindeki yerine de değinilmiştir. Yazının son kısmında ise çalışmamıza konu olan varsağ̀ ve şairi tanıtılmıştır. Bu bölümde, incelenen varsağının, şair tarafindan nasıl anlaşıldı̆̆ ortaya konmaya çalışılmıştır. XVII. yüzyılda yaşayan İbrahîm Ziyâeddîn'in Divan'ı dışında başka bir eseri elimizde mevcut değildir. Biyografik kaynaklarda kendisine dair malumata rastlamadı̆̆ımız şair hakkında bilinenler, bu divanda aktardı̆̆ bilgilerden ibarettir. Kendi çağdaşlarına nispetle edebî açıdan zayıf sayılabilecek İbrahîm Ziyâeddin, yine de pek çok bakımdan divan şiiri geleneğinin dışında tutulamaz. Bir divan şairi olarak onun varsă̆ yazması, bu gelenekte görülmeyen bir durum olmamakla birlikte söz konusu şiir, özellikle şekil bakımından halk şiirindeki geleneksel varsağılardan farklıdır. Şiir metninden anladiğımıza göre İbrahim Ziyâeddîn, varsağıyı şekil ya da tür olarak algılamayarak daha geniş bir açıdan yorumlamıştır. Yani varsağıya bir üslup ve anlatım özelliği olarak yaklaşmıştır diyebiliriz.
\end{abstract}

Anahtar Kelimeler: Nurî, İbrahîm Ziyâeddin, Varsă̆l, XVII. yüzyıl, Üslup

\section{WHEN A DIVAN POET LOOKS A DIFFERENT ASPECT AT VARSAGI}

\begin{abstract}
In this study we focused on the a poem titled "varsă̆l" written by Ibrahim Ziyaeddin, whose mahlas is Nuri and who lived in XVII. century. Firstly, we drew the conceptual framework of "varsağl" in folk poetry tradition. We tried to emphasize the foregrounding characteristics of "varsağl" especially as a literary term avoiding to quote the common descriptions and properties reported in the literature. In the second place, we gave place to how Divan poets evaluated folk poetry and "varsağl" dealing with the effects of their views on classical Azerbaijan poetry. At the final part of the study, we introduced the
\end{abstract}


"varsăgl" and its poet abovementioned concentrating on how the poet himself apprehend the "varsăgl". We have no other works of İbrahim Ziyaeddin except his Divan. All we know about Ibrahim Ziyaedin comes from his Divan since there is no word related to him on bibliographic records. Although his literary power is far behind the poets of his age, he still must be considered in the circle of Divan poetry. As wellas his varsagl writing is not an unpresecented situation as a Divan poet in classical Turkish poetryt radition, his mentioned poem is different from the classical varsagus in folk poetry tradition especially in point of form. The "varsa $\breve{g}$ " in his Divan is different from the examples we encounter in folk poetry. We conclude that, Ibrahim Ziyaeddin interpret the "varsağl" in a boroad manner, since his poem didn't meet the requirements of "varsağl" in terms of form and genre pecularities. In other words, he reconceptualised "varsağl” as a stylistic feature.

Key Words: Nuri, İbrâhîm Ziyâeddîn, Varsă̆ı, XVII Ceuntry, Style

\section{GíRIŞ}

Divan ve halk şiirinin aynı kültürel kök ve kodlara dayanması, bu saha çalışanlarınca bilinen bir gerçektir. Bu yüzden söz konusu şiir geleneklerin "gül-i ra'nâ"ya yani "çift renkli çiçeğ"e benzetilmesi adetten sayılmıştır.

Bu çift renkli çiçeğin, yani halk ve divan şiirlerinin kökü aynı kültür toprağına salındığından, iki şiir geleneği arasındaki paralellik tabiî olmakla beraber üzerinde durulması gereken bir noktadır. Özellikle XVII ve XVIII. asırda bu şiir geleneklerinin vezin, konu, tema kimi zamanda da şekil bakımından yakınlaşması bahsettiğimiz tabiî ortamın belirginleşmesine sebep olmuştur.

Örneğin XVII. asır şairi Feyzînnin Şem ü Pervâne adlı eserini hece vezniyle yazması, sosyal bilimlerde herhangi bir konuda değişik bir örnekle karşılaşmışsak bunun birden fazla olma ihtimalinin her zaman olduğuna (Kurnaz, 1997: 187) işaret eder. Öte yandan XVII. asırdan itibaren halk şairlerinin kimi aruzlu nazım biçimlerini tercihi, hem etkileşimin çift yönlü olduğunu hem de istisnaî örneklerin bazen yaygınlaştığını gösterir. Ayrıca, halk ve divan şiirlerinin başlangıçtan beri ortak kelime kadrosu, konu, tema ve mazmunları kullanması, söz konusu şiir gelenekleri arasındaki geçişliliğin devamını ve canlılığını sağlamıştır. İşte bu duruma bağlı olarak divan şairlerinin zaman zaman, -bizim ele alacağımız konuda görüleceği gibi-sadece müşterek mazmun ve kelime kadrosu değil, biçim ve üslup olarak da halk şiirine yöneldiği görülür.

\section{Edebî Bir Terim Olarak Varsağı}

Türk edebiyatı çalışmaları esnasında varsağıyı derinlemesine ele alan Fuad Köprülü onu, "Varsaklara mahsus bir beste ile terennüm edilen bir nevi halk türküsü” diye tanımlayarak varsağıyı türküden farklı görmez. Buna göre türkü, türkmânî, koşma tarzlarından ancak bestesiyle ayrılan varsağı kelimesinin, eskiden türkü kelimesiyle aynı manada anlaş1ldığı açıktır (Köprülü, 2003: 236237). Ahmet Talat Onay, varsağıya coğrafî bir sınırlama getirerek, "çok eskiden Tarsus civarında oturan Varsak aşiretinin söyledikleri bir nevi besteli kayabaşılar (takliden söylenen nazımlar)" diye bir yargıda bulunur. Ayrıca varsağıların sekiz veya onbirli hece ölçüsüyle yazıldıklarını belirterek "koşma yahut türkü gibi" 
olduklarına dikkat çeker (Onay, 1996: 63). Dizdaroğlu, varsağıyı semaîye benzetmekle birlikte uyak düzeni bakımından koşmadan farklı görmez. Onu koşmadan ayıran tek yön ezgisidir, (Dizdaroğlu, 1968: 244) der.

Varsağıların biçimi ile üslubu hakkında da ansiklopedi maddeleri ve çeşitli kaynaklarda kalıplaşmış, birbirinin tekrarı olan ifadelere rastlarız. Buna göre varsağılar yiğitçe, mertçe bir üslupla söylenir. Bu da varsağ 1 içinde "behey", "bre", "hey" ve "hey gidi" gibi ünlemlerle sağlanır (Dilçin, 2000: 336). Ayrıca beste olarak dinlendiğinde, söz ve müziğinde meydan okuyan, babacan, erkekçe bir hava hissedilir (Kaya, 2007: 65). Önceki araştırmacılar içinde, varsağıların bestesi dışında farklı bir cephesine dikkat çeken kişi Fuad Köprülü'dür. Köprülü'ye göre varsağı ve diğer bazı benzer türler, eski geleneksel edebî mahsuller dışında "sırf lirik mahiyette birtakım hissî aşk şiirleri ve türküleri"dir. Bu ürünler, "öyle ma'şerî duyguların, sosyal ülkülerin değil, sırf ferdî ihtiyaçların ifadesi"dir ve "umumîyetle millî vezin"de yazılmış olup "eski kavmî edebiyat devresi"nden kalmıştır. Bunlar "türkü, türkmânî, varsağı gibi kavmî aidiyetleri veya koşma, deyiş ve kayabaşı gibi kırsal menşei ya da beste ile beraber okunmayı gerektiren eserlerdir” (Köprülü, 2003: 236-237).

Yukarıda bahsedilen geleneksel varsağı anlayışına günümüzde ilk ciddî itiraz, Öcal Oğuz tarafından yapılır. O, bu konuda, "yeteri kadar araştırma yapılmadan ve az sayıda varsağı örneğinden hareket edilerek tarifler" yapıldığı ve "Türkiye sahasındaki kaynakların araştırılmasıyla bile" söz konusu yargıların çürütülebileceği kanaatindedir (Oğuz, 2001: 34). Türkiye sahası dışında Azerbaycan ve Türkmenistan'da da varsağı hakkında yapılan çalışmaları gözden geçiren Oğuz öncelikle, bu sahalardaki varsağıların kimi şekil farklılıklarına dikkat çeker. Ayrıca Türkiye sahasındaki araştırmalarda vurgulanan kendine has ünlemler kullanılan şiirlerin varsağı diye adlandırılması hususiyetinin artık geçerliliğini kaybettiğini söyler. Öte yandan Türkmenistan sahasında varsağılara aşk ve sevgi makamı denilmesinden yola çıkarak gurbet, hasret, aşk, tabiat, ölüm gibi çok farklı temaların varsağılarda işlendiğine dikkat çeker (Oğuz, 2001: 4041). Oğuz'un varsağılar hakkındaki son kanaati şöyledir:

"Eldeki belgelerden, varsağının ozanlık geleneğinden günümüze gelen bir terim olduğu anlaşılmaktadır. Halk şiiri türlerinin yaygın olarak adlarını ezgisinden aldıklarını da hesaba kattığımızda, varsă̆ının sanıldı̆̆ gibi bir şekil veya tür adı olmaylp bir dönemin halk şairleri olan "varsaklar" tarafindan yaratılan şiirlerin tamamının genel adı olabileceği ihtimali daha kuvvetli görünmektedir. Varsağlların, halk şiirinin temel özelliğine bağlı olarak belirlenmiş bir şekil veya konu sinırlaması bulunmayan ancak klasik musikîdeki "makam" karşıllğı sayllabilecek ezgileriyle birbirinden ayrılan ve bu ezgileri de coğrafi ve kültürel faktörlerin etkisiyle zaman içinde değişen ve çeşitlenen, Varsaklar tarafindan yaratılan şiirlerin tamamının adı olduğunu söyleyebiliriz" (Oğuz, 2001: 42). 
Bizim ele alacağımız örnekte de görülebileceği gibi, umumî olarak gelenekte özelde ise divan şiiri geleneğinde varsağı, kimi özel tema ve konu içerme dışında farklı bir üslup özelliği olarak da anlaşılmaya müsaittir.

\section{Divan Şiiri Geleneği ve Varsağı}

Osmanlı sahası şuarâ tezkireleri içinde varsağı hakkında bilgi veren ilkbüyük olasılıkla da tek ${ }^{1}$ - kaynak Gelibolulu Âlî’nnin Künhü’l-Ahbâr adlı eseridir. Âlî bu konuda şöyle der: "Hafí olmaya ki Osmân Han ve Orhan Han ve Sultân Murâd Han zamânlarında şu'arâdan kimse zuhûr itdügi ma'lûm degüldür. Mücerred sâde nazma kâdir ba'zı varsă̆l-gûylar zuhuru bile igen şöhret bulmamışdur" (İsen, 1994: 10). Görüldüğü gibi "mücerred nazma kâdir...bulmamıştır" ifadesinden müellifin varsağıları, ibtidaî veya sanatsal anlatımdan uzak gördüğü anlaşılmaktadır. Oysa, Varsaklar'ın Anadolu'da Selçuklular devrinden itibaren görüldüğü göz önüne alınırsa, Osmanlı sahası şuarâ tezkirelerinin varsağıyı ne kadar göz ardı ettiği daha iyi anlaşılır.

Şükrü Elçin, Kanunî'nin oğlu Bâyezıd'ın öldürülmesi üzerine Kul Pîrî'nin yanık-romantik bir edayla yazdığı varsağıdan bahseder (Elçin, 2000: 300). Bu da varsağının, klasik divan şairlerince olmasa da, devrin geleneği bakımından takip edildiğini göstermektedir. Yine Köprülü, Evliya Çelebi’ye dayanarak Sultan IV. Murad'ın, musahibi Musa Çelebi'nin öldürülmesi üzerine yazdığı bir varsağıyı ${ }^{2}$, Evliya Çelebi'nin onun huzurunda okuduğunu söyler (Köprülü, 2003: 236). Bu varsağı mersiye havasında olup duygulu bir edayla dile getirilmiştir.

Azerbaycan sahasındaki klasik ya da yarı klasik şairler varsağıya, Osmanlı şairlerine oranla daha fazla ilgi göstermişlerdir. Çünkü zannımızca, Azerî Türklerinin siyasî otorite kurdukları Azerbeycan ve İran'da merkezîleşmenin, dolayısıyla klasik şairlerin yetişmesine ortam sağlayan saray çevresinde gelişen edebiyatın daha geç ortaya çıkması, bir Halk şiiri ürünü olan varsağının bu bölgelerde daha uzun süre canlı kalmasına sebep olmuştur. Örneğin varsağıya olan ilgi Azerbaycan ve İran'da uzun müddet sonra merkezî otorite sağlayan Şâh İsmail Hatayî devrinde de devam etmiştir. Sadık Bey Afşar, Mecmau'l-Havâs adlı eserinde, onun sarayında çalışan Mehmed Bey Şemsî’nin varsağı şeklinde şiirler icra ettiğini söyler (Kaya, 2007: 764). Yine XVI. asrın ikinci yarısında, Rey ve Şehriyâr havalisindeki Varsak kabilesine mensup Tahmâsp Kulı Gul'un, önce Kandehar'da ve sonra da Hindistan Türk saraylarında, varsağı ve türkü okumakla şöhret kazandığ1 ve başka türkücülere üstünlük sağladığı bilinmektedir (Köprülü, 2004: 70). Dolayısıyla Osmanlı

1 Köprülü, Âşık Çelebi’nin Yunus Emre'nin “varsağı üslubunda eserleri olduğu”nu söylüyorsa da (Köprülü, 2003: 236) Âşık Çelebi tezkiresinin Yunus emre maddesinde böyle bir bilgi yer almamaktadır (bkz. Kılıç, 2010: II/689).

2 Bu varsağının kaynaklarda geçen kısmı şöyledir: Yola düşüp giden dilber/Musa'm eğlendi gelmedi/Yoksa yolda yol(u) mu şaşt//Musa'm eğlendi gelmedi (Dizdaroğlu, 1968: 245). 
sahasında da, halk şiiri geleneğine bağlı veya Azerbaycan sahası ile bir şekilde ilgisi olan klasik divan şairlerinin varsağı söylemesi ihtimal dahilindedir.

Ancak Köprülü'nün de belirttiği gibi, eski divan ve tezkireler genel olarak gözden geçirildiğinde, eskilerin halka ait mensur hikaye, türkü ya da koşmaları hakir gördüğü anlaşılır. Mesela Âşık Çelebi, halk arasında okunmaya mahsus sade bir eser yazmasından dolayı Hamzevî'yi şairler zümresinden kabul etmez (Köprülü, 2004: 190). Bu tavır, halk şiirinden divan şiirine sirayet eden nazım şekillerine karşı dahi değişmemiştir. Örneğin Sehî Bey'in Heşt Bihişt adlı tezkiresinde, söylediği bir beyitten ${ }^{3}$, halk şiirindeki mânînin etkisiyle oluşan tuyuğun küçümsendiği anlaşılmaktdır (İpekten, 1997: 82). Ama bu durum divan şairlerinin, halk şiirin üslup, tema ve imajlarından hiçbir zaman faydalanmadığ anlamina gelmez.

\section{İbrâhim Ziyâeddîn ve Varsağısı}

Nûrî mahlaslı İbrâhim Ziyâeddîn'e ait eksik bir divan, Millî Kütüphane yazmaları içinde Yz A 5730 kaydında yer almaktadır. Bu divan baş ve son kısımlarından eksik olup 2 mesnevi, 12 kaside, 1 müseddes, 1 terkib-i bend, 1 müstezad, 3 satranc, 1 şikayetname, 1 muhammes, 1 matla, 7 tahmis, 1 varsağ , 72 gazel içerir ve 58 varaktır. Bu yazmanın kütüphane kaydına göre şair 1044/1634 tarihinde hayattadır. Yaptığımız araştırmalara göre şairin Süleymannâme adlı başka bir eserinden de söz ediliyorsa da henüz bu esere ulaşamadık. Şair hakkında herhangi bir biyografik kaynakta da bilgiye rastlanmadı. Ancak elimizdeki tek eseri olan divanına baktığımızda çeşitli şiirlerinden Eflak, Boğdan, İran ve Azerbaycan gibi bölgelere seyahat etmiş olabileceği anlaşılmaktadır.

Ayrıca divanının 25a-28b varakları arasında yer alan bir kasidenin "Şikâyet-nâme ez-Felek be-Ümîd-i Lutf-ı Husrev-i Âdil" başlı̆̆ını taşıması ve denizcilik terimleriyle donatılarak muhtemelen devrin kaptan-1 deryâsına sunulması, şairin denizcilik mesleğine mensup veya bu mesleğe aşina olduğunu göstermektedir. Şairin, Azerbaycan ve İran'a seyahati ile denizciliğe olan yakınlığının, varsağı yazmasında etkili olduğu kanaatindeyiz.

O, klasik divan şairi ölçülerine göre, nazım tekniği açısından zayıftır. Türkçe kelime ve ibareleri sıkça kullanmasından dolayı aruzu uygularken yer yer zihâflar yaptığını görmekteyiz. $\mathrm{Bu}$ da klasik bir eğitim almadığınının göstergesidir. Öte yandan çeşitli şiirlerinde, "gömgök vücûd, güp güp dökmek, kllı kırk rîze (parça) etmek, yumruğu altına gözetmek, kaynar kaynar fokurdamak, göz kıpmak, göy yerden ot bitmek" gibi konuşma dili ve halk ağzına ait tabirlere rastlanır. Bu da, halk geleneğine uzak olmadığına işarettir.

Ancak; Hâletî, Na'tî, Gusârî, Nahlî, Süheylî, Riyâzî, Hafız Paşa gibi kendi devrinde veya öncesinde yaşayan şairlerin divanlarına nazireler yazması ve Hafız-1 Şirâzî’nin divanının ilk beytini esas alarak ona bir nazire kaleme alması,

\footnotetext{
${ }^{3} \mathrm{Bu}$ beyit şöyledir: Bülbül sadâsı gibi şi’r-i Sehî güzeldür/Eş’âr-1 gayrılar hep ana göre tuyuğdur.
} 
hem dönemindeki divan şiiri geleneğini takip ettiğinin hem de, klasik şiir yazma yeteneğini geliştirme peşinde olduğunun ispatıdır. Dolayısıyla İbrahîm Ziyâeddîn'i, divan şiiri geleneği dışında saymak mümkün değildir.

İbrahîm Ziyâeddîn'in çalışmamıza konu olan varsağısı, divanında 36b/37a varakları arasında yer alır. Bu şiirin metni şöyledir:

\section{Varsă̆ı}

Nice bir ben âşı-ı âvâreni zâr idesen

Şive vü nâz u kirişmen ile bîzâr idesen

Hîç düşer mi gayrilarla sana bâzâr idesen

Evvelâ gönlüm alup benden girü âr idesen

Kaçma benden servi boylum yohsa ben oldum helâk

Ben senün bir âş̧ı-ı sâdık kulun kurbânunam

Pâdişâhum her ne dirsen bende-i fermânunam

Görmedin şâhum yüzüni vâlih u hayrânunam

Ben kabûl itdüm eger dirsen senün sultânunam

Kaçma benden servi boylum yohsa ben oldum helâk

Sabra tâkat kalmadı cânum esirge âşılkun

Hak bilür kim ben kulundur âşıkun hem sâdıkun

Her cihetle bendenüm aşkun yolında fâyikün

Ben hakîün her ne denlü olmaz isem lâylkun

Kaçma benden servi boylum yohsa ben oldum helâk

Hasretile ben kulun lutf eyle mahzûn eyleme

Zârî zârî ağladup yaşumu Ceyhûn eyleme

Yüzüni göster kerem kll beni Mecnûn eyleme

Kulunum şâhum senün kan ile kânûn eyleme

Kaçma benden servi boylum yohsa ben oldum helâk

Nûrî-i bî-çâre cânin yoluna eyler fidâ

Tek hemân makbûle geçsün cân-ı şîînüm şehâ

Başum ile cânumı senden sakınmam dil-berâ

Yok durur kizbüm bu sözler içre vâklfdur Hudâ

Kaçma benden servi boylum yohsa ben oldum helâk

Varsağı başlıklı yukarıdaki şiir, fâ'ilâtün fâ'ilâtün fâ'ilâtün fâ'ilün vezniyle yazılmış olup beş adet beş dizeli bendden oluşmuştur. Bilindiği gibi Türk halk şiirinde varsağılar, genelde dörtlüklerle yazılır ve biçim olarak semâî, koşma ya da türküye benzer. Semâîlerin hece vezniyle yazılanları koşma tipindedir. Aruzla yazılanları ise mefâ'îlün mefâ'îlün mefâ'îlün mefâ'îlün kalıbında olup gazel, murabba, muhammes, müseddes şeklindedir. Koşmanın 
kafiyelenişi, baba-ccca-ddda... veya ilk dörtlüğ̈̈ xa xa veya bbba biçimindedir. Türküler ise kavuştaklarına göre pek çok kafiyeleniş şekline sahip olup genelde aaxa-bbxb-ccxc-ddxd...; bbba-ccca-ddda-eeea..; aak-bbbk-ccck-dddk.. şekillerinde kafiyelenir.

İncelediğimiz varsağı ilk bakışta, aruzla yazılmış ve beş dizeli bendlerden oluşmak bakımından halk şiiri açısından aruzlu semâî olarak değerlendirilebilir. Ancak vezin bakımından aruzlu semâi ile çelişir. Şekil açısından ise, aaaaAbbbbA-ccccA kafiyelenişiyle yani son misraın aynen tekrarıyla Muhammes-i mütekerrire bire bir uymaktadır. Kısacası şair aslında, mütekerrir bir muhammes yazıp buna varsağı başlığını koymuştur. Mütekerrir muhammeslerden kasıt, her bendinde bir veya daha fazla misrain aynen tekrar etmesidir ve bunda, tekrarlar sonucu ortaya çıkan ahengin etkili olduğu söylenebilir (Erdoğan, 2002: 65-66). Belki bu şiire varsağı başlığının, müstensih hatasıyla konulduğu da düşünülebilir. Ancak, müstensih neden divan şiiri geleneği içindeki bir şairin muhammesine, mesela müseddes ya da başka bir divan şiiri nazım şeklini yanlışlıkla yazmamış da daha uzak ihtimal olan varsağı başlığını atmıştır? Bu başlık bilinçli olarak atılmışsa şair, yazdığı şiirle varsağı arasında nasıl bir ilgi kurmuş olabilir?

Daha önce belirttiğimiz gibi bu divan, baş ve sondan eksik olduğundan nüshanın müellif hattı $\mathrm{m} 1$ yoksa başka bir müstensih tarafından $\mathrm{m}$ yazıldığına dair elimizde bir kanıt mevcut değildir. Ayrıca, divan içindeki şiirlerde de nüshanın kim tarafindan yazıldığına dair bir işaret yoktur. Dolayısıyla incelediğimiz şiire kim tarafından başlık atıldığı belirsizdir. Şiirlerde ve şiir başlıklarında kullanılan yazı türünün aynı yani talik olması, şiirlere sonradan müdahale edilme ihtimalini de ortadan kaldırmaktadır. Daha da önemlisi, divanın farklı yerlerinde kimi şiirlere, "Berâ-yı Mehmed Efendi Mukâbili, Pend-i Nûrî, Kasîde-i Beççe” vb. başlıkların atılması, şairin/müstensihin bu konuda tesadüfî hareket etmediğini göstermektedir. Kısacası söz konusu şiire, şuurlu bir şekilde ve belirli bir maksatla "varsağı" başlığının atılmış olma ihtimali yüksektir.

$\mathrm{Bu}$ varsağıya öncelikle dil bakımından yaklaştığımızda, Arapça-Farsça kelime ve tamlamaların nispeten az olduğu görülmektedir. Ayrıca derin edebî sanatlar ile karmaşık mazmunlara da hemen hiç yer verilmemiştir. Şiire konu bakımından baktığımızda, aşığın sevgilisinden çektiği cevirlerden şikâyet edip kendisine iltifat etmemesinden bahsettiğini görmekteyiz. Zaten klasik edebiyatımızın temel konusu olan aşk, muhammeslerin yarısından fazlasının da konusudur (Erdoğan, 2002: 165). Bu şiirde, sevgilinin nazı ile işvesi, sevenin kul, sevgilinin padişah olması, aşığın sabır ve tahammülünün kalmaması ile buna bağlı olarak sürekli inleyip ağlaması, canını seve seve maşukuna feda etmesi gibi divan şiirinin geleneksel temaları da mevcuttur. Yani şiir, konu ve söyleyiş bakımından divan şiiri geleneğinden uzak değildir. O zaman bu noktada varsağının şairi, "dil ve üslup bakımından ortaya koyduğu farklı bir uygulamayı $\mathrm{m} 1$ varsağ saymaktadır" sorusu akla gelmektedir.

Yukarıda, Öcal Oğuz'un yurt içi ve yurt dışında yazılmış varsağılar üzerine yaptığı incelemelerde varsağının, şekil-tür adı olmayıp bu açılardan 
sınırlandırılmaması ve klasik musikîde makam karşılı̆̆ 1 olarak algılanabilecek ezgileriyle farklılıştı̆̆ına dair görüşlerini aktarmıştık. Bu görüşler ele aldığımız varsağıyı yorumlamamızı kolaylaştırmaktadır. Şöyle ki; Klasik musikîdeki makam, divan şiirinde vezin veya konu/tema olarak karşılanır. Dolayısıyla bu varsağıda şair, içten, yanık ve romantik aşk anlatısını sade bir dille ele almak bakımından şiirini varsağı diye nitelendirmiş olabilir. Yani İbrahîm Ziyâeddîn, bir divan şairi olarak halk şiirinden dil ve üslup bakımından faydalanmayı tercih etmiştir. Bir bakıma, içten yanık duyguları samimiyetle arz etmeyi, varsağ nitelemiştir. Ele aldığımız örnek ve üzerinde yaptığımız incelemeler bizi, halk şiirine ait tür ve şekilleri kullanan kimi divan şairlerinin bu şiirlerine, üslup ve anlatım biçimi bakımından daha farklı ve dikkatli yaklaşmamız gerektiği düşüncesine sevk etmektedir.

\section{SONUÇ}

Halk edebiyatı araştırmalarının ulaştığı en yeni neticelerde geniş perspektiften değerlendirilen varsağı, XVII. asırda İbrahîm Ziyâeddîn tarafindan bir dil, üslup ve anlatım özelliği olarak algılanmıştır. Bu üslup ve anlatım özelliğinin temel niteliği, geleneksel temaları içermekle beraber sade dile sahip olması, Farsça-Arapça kelime ve tamlamalara olabildiğince az yer vermesi, içten, coşkulu ve lirik olması ile konuşma diline yaklaşmasıdır.

Dolayısıyla halk ve divan şiiri ilişkileri, sadece biçim özellikleriyle değil konu, tema ve dil/üslup açısından da dikkatle irdelenmelidir.

\section{KAYNAKLAR}

Ankara.

DíLçìn, Cem (2000), Örneklerle Türk Şiir Bilgisi, TDK Yayınları,

DİZDAROĞLU, Hikmet (1968), "Halk Şiirinde Türler". Türk Dili Dergisi, say1: XIX/20, s. 186-293.

ELÇİN, Şükrü (2000), Halk Edebiyatına Giriş, Akçağ Yayınları, Ankara.

ERDOĞAN, Mustafa (2002), Türk Edebiyatında Muhammes, Kültür Bakanlığı Yayınları, Ankara.

İbrahîm Ziyâeddîn, Dîvân, Millî Kütüphane, Yz. A. 5730, Ankara.

İPEKTEN, Haluk (1997), Eski Türk Edebiyatı Nazım Şekilleri ve Aruz, Dergâh Yayınları, İstanbul.

İSEN, Mustafa (1994), Künhü'l-Ahbâr'ın Tezkire Kısmı, AKMY, Ankara.

KAYA, Doğan (2007), "Varsağı". Ansiklopedik Türk Halk Terimleri Sözlüğ̈̈, s. 764-765.

KILIÇ, Filiz (2010), Aşık Çelebi Meşâirü'ş-Şu'arâ İnceleme Metin, İstanbul Araştırmaları Enstitüsü Yayınları, İstanbul.

KÖPRÜLÜ, Fuad (2004), Edebiyat Araştırmaları 1. (Yay. Haz. Orhan Köprülü), Akçağ Yayınları, Ankara.

Köprülü), Akçağ Yayınları, Ankara. (2004), Edebiyat Araştırmaları 2. (Yay. Haz. Orhan 
Orhan Köprülü), Akçă̆ Yayınları, Ankara.

(2003), Türk Edebiyatında Illk Mutasavviflar, (Yay. Haz.

KURNAZ, Cemal (1997), Türküden Gazele, Akçağ Yayınları, Ankara.

OĞUZ, M. Öcal, (2001), Halk Şiirinde Tür, Şekil ve Makam, Akçă̆ Yayınları, Ankara.

ONAY, Ahmet Talat (1996), Türk Halk Şiirlerinin Şekil ve Nevi, (Yay. Haz. Cemal Kurnaz), Akçağ Yayınları, Ankara. 